\title{
Clouds and hazes
}

\section{from R.G. Knollenberg}

THE Venus cloud and haze system summarized in Table 1 is planetary in nature with an enormous vertical extent of 50-60 $\mathrm{km}$. The clouds are rather tenuous and were found to have an average visibility of about $1 \mathrm{~km}$ by early Venera nephelometer (particle backscatter photometer) measurements ${ }^{1}$. The main cloud deck is at an altitude of $45-70 \mathrm{~km}$ and includes particles of various compositions ${ }^{2}$. Upper, middle and lower cloud regions are easily defined by transition layers and changes in size properties. Haze layers overlie and underlie the main cloud deck.

Through an analysis of polarimetry data, Kawabata has shown that the upper submicron aerosol haze has an average optical depth of about 1 in its most dense polar regions where it is a distinct layer above the main cloud deck ${ }^{3}$. In the equatorial and mid-latitude regions, it is about one-tenth as dense and is mixed with $2 \mu \mathrm{m}$ diameter monodispersed $\mathrm{H}_{2} \mathrm{SO}_{4}$ cloud droplets at the top of the main cloud deck. The haze particles also have optical and physiochemical properties consistent with $\mathrm{H}_{2} \mathrm{SO}_{4}$.

Ragent and Blamont's nephelometer data show a sharp base for the main cloud deck at $47-50 \mathrm{~km}$ at four different Pioneer Venus entry sites but thin filaments are also evident below the nominal cloud base ${ }^{4}$. Knollenberg and Hunten have shown that the size distribution is generally multimodal throughout the main cloud deck, which has an optical depth of 20-30 (ref.5). There are three size modes identified as mode 1 aerosol, which varies in composition with altitude; mode $2 \mathrm{H}_{2} \mathrm{SO}_{4}$ droplets; and mode 3 , which appears to include $\mathrm{H}_{2} \mathrm{SO}_{4}$ droplets and perhaps crystals of unknown composition. Below the main cloud deck, small haze particles of low number density extend down to approximately $30 \mathrm{~km}$, where all particles essentially disappear.

Mode 1 is highly variable in all cloud regions and has been characterized as a background aerosol population with high number density but little optical depth except in the UV. Toon has shown that, in the upper cloud region, the mode 1 aerosols have a higher refractive index and seem to be rich in sulphur compounds ${ }^{6}$. In the lower cloud region, $\mathrm{H}_{2} \mathrm{SO}_{4}$ appears more plausible. Below the cloud deck, the mode 1 aerosols, which comprise the lower thin haze, appear to be desiccation products (cores) of cloud particle growth and decay.

The mode $2 \mathrm{H}_{2} \mathrm{SO}_{4}$ droplets are probably several months old in the upper cloud region unless vertical exchange is faster than suspected, but perhaps only

R.G. Knollenberg is President of Particle Measuring Systems Inc., 1855 South 57th Court, Boulder, Colorado 80301.

Table 1 Summary of Venus cloud and haze properties

\begin{tabular}{|c|c|c|c|c|c|c|}
\hline Region & $\begin{array}{l}\text { Altitude } \\
(\mathrm{km})\end{array}$ & $\begin{array}{c}\text { Temperature } \\
\text { (K) }\end{array}$ & $\begin{array}{c}\text { Optical } \\
\text { depth } \\
\tau\end{array}$ & $\begin{array}{c}\text { Av. no. } \\
\text { density } \\
\text { (per } \mathrm{cm}^{3} \text { ) }\end{array}$ & $\begin{array}{l}\text { Mean } \\
\text { diameter } \\
(\mu \mathrm{m})\end{array}$ & Composition \\
\hline Upper haze & $70-90$ & $225-190$ & $0.2-1.0$ & 500 & 0.4 & $\mathrm{H}_{2} \mathrm{SO}_{4}$ \\
\hline Upper cloud & $56.5-70$ & $286-225$ & $6.0-8.0$ & $\begin{array}{c}(1)-1,500 \\
(2)-50\end{array}$ & $\begin{array}{l}\text { Bimodal } \\
0.4,2.0\end{array}$ & $\mathrm{H}_{2} \mathrm{SO}_{4}+$ sulphur \\
\hline Middle cloud & $50.5-56.5$ & $345-286$ & $8.0-10$ & $\begin{array}{c}(1)-300 \\
(2)-50 \\
(3)-10\end{array}$ & $\begin{array}{c}\text { Trimodal } \\
0.3,2.5 \\
7.0\end{array}$ & $\begin{array}{l}\mathrm{H}_{2} \mathrm{SO}_{4}+ \\
\text { crystals (?) }\end{array}$ \\
\hline Lower cloud & $47.5-50.5$ & $367-345$ & $6.0-12$ & $\begin{array}{c}\text { (1) }-1,200 \\
\text { (2) }-50 \\
(3)-50\end{array}$ & $\begin{array}{c}\text { Trimodal } \\
0.4,2.0 \\
8.0\end{array}$ & $\begin{array}{l}\mathrm{H}_{2} \mathrm{SO}_{4}+ \\
\text { crystals (?) }\end{array}$ \\
\hline Lower haze & $31-47.5$ & $482-367$ & $0.1-0.2$ & $2-20$ & 0.2 & $\mathrm{H}_{2} \mathrm{SO}_{4}+$ aerosol \\
\hline $\begin{array}{l}\text { Pre-cloud } \\
\text { layers }\end{array}$ & $46,47.5$ & 378,367 & $0.05,0.1$ & 50,150 & $\begin{array}{c}\text { Bimodal } \\
0.3,2.0\end{array}$ & $\begin{array}{c}\mathrm{H}_{2} \mathrm{SO}_{4}+ \\
\text { aerosol }\end{array}$ \\
\hline
\end{tabular}

hours old in the lower cloud region. At upper altitudes, $\mathrm{H}_{2} \mathrm{SO}_{4}$ droplets are likely to be contaminated after scavenging aerosol over their long lifetime. Near cloud top, $\mathrm{H}_{2} \mathrm{SO}_{4}$ vapour should be sufficiently supersaturated to support a bimodal population; that is, small droplets can nucleate and grow even in the presence of an existing larger droplet population. The mode $2 \mathrm{H}_{2} \mathrm{SO}_{4}$ droplets nucleate and grow in the upper cloud region. Knollenberg and Hunten observe a gradual increase in number density descending through the main cloud deck. The mode regenerates through condensation in the lower layers. Its size distribution is exceedingly narrow at any one altitude - growth models of Turco and Toon indicate that dominant but competitive droplet diffusional growth can explain this ${ }^{7}$. The mode 2 distribution is uniform over most of the planet and is indicative of its extreme stability.

Analysis of particle image data by Knollenberg and Hunten showed the largest mode 3 particles to be asymmetric and suggested a crystalline species interpretation. Toon has shown that the radiative flux and single particle optica data are consistent without a crystalline species ${ }^{8}$ and favours $\mathrm{H}_{2} \mathrm{SO}_{4}$ droplets. Additional measurements will probably be required to resolve this controversy.

The entire Venus cloud system has an optical depth of 20-35 at visible wavelengths. Taylor reports a radiometric albedo of $0.77-0.82$, increasing from equator to pole? . His IR radiometer data have revealed a strong dipole circulation near the poles. Tomasko finds single scattering albedoes ranging from a low of 0.995 in the upper cloud region to 0.999 in the lower cloud region ${ }^{10}$. For most of the radiometric spectrum the planet appears featureless; however, fascinating contrasts are observed in the UV via partially understood absorption processes. Pollack and Esposito find that sulphur dioxide is responsible for absorption at short UV wavelengths, but the identity of the absorber visible from Earth in the near-UV remains unknown ${ }^{11,12}$. Particulate sulphur (mode 1) appears to be a possible choice for secondary absorber. The related question of how the physical and/or chemical processes at the cloud top act to bring about the horizontal variability of these absorbing constituents is still a puzzle.

The main cloud deck is embedded in the zonal circulation at altitudes of greatest wind velocity and vertical wind shear. The clouds are all of stratiform morphology. Cloud particle growth is not strongly influenced by either the large-scale circulation or the latent heat released during condensation. The clouds are most strongly influenced by radiative exchanges. Because of the temperature extremes, there is a rather large scale of $\mathrm{H}_{2} \mathrm{SO}_{4}$ droplet growth times ranging from months in the upper hazes to hours in the lower cloud region. There is little evidence for the existence of large precipitation particles. Known processes for the formation of the lightning observed by Ksanformaliti and Scarf ${ }^{13,14}$ require both. If cloud processes generate the lightning, then much larger undetected particles must exist. Scarf has suggested that the Venus lightning is phaselocked with the surface and may be solely the result of volcanic activity ${ }^{15}$.

1. Marov, M.Ya., Lebedev, V.N., Leptaev, V.Ye. \& Maknylov, X.K. Acad. Sci. USSR Space Res. Inst. 5 (1979).

2. Knollenberg, R.G. \& Hunten, D.M. Science 205, 70 (1979).

3. Kawabata, K. et al. J. geophys. Res. 85, 8129 (1980)

4. Ragent, B. \& Blamont, J. J. geophys. Res. 85, 8089 (1980)

5. Knollenberg, R.G. \& Hunten, D.M. J. geophys. Res. 85, 8039 (1980).

6. Toon, O.B. (personal communication)

7. Turco, R. \& Toon, O.B. Abstr. Proc. int. Conf. Venus Environ., 58 (1981).

8. Toon, O.B. \& Blamont, J. Abstr. Proc. int. Conf. Venus Environ., 59 (1981).

9. Taylor, F.W. et al. J. geophys. Res. 85,7963 (1980).

10. Tomasko, M.G., Doose, L.R., Smith, P.H. \& Odell, A.P. J. geophys, Res, 85, 8167 (1980).

11. Pollack, J.B. et al. J. geophys. Res. 85, 8141 (1980).

12. Esposito, L.W. J. geophys. Res. 85, 8151 (1980)

13. Ksanfomaliti, L.V. et al. Pisma Astr. Zh. 5, 229 (1979).

14. Scarf, F.L., Taylor, W.W.L., Russell, C.T. \& Brace, L.H. J. geophys. Res. 85, 8158 (1980)

15. Scarf, F.L., Taylor, W.W.L., Russell, C.T., Elphic, R.C \& Luhmann, J.G. Abstr. Proc. int. Conf. Venus Environ., 55 (1981) 